\title{
INTERNET ADDICTION AND CYBERCHONDRIA - THEIR RELATIONSHIP WITH WELL-BEING
}

\author{
Eliza Ivanova \\ elizaxivanova@gmail.com
}

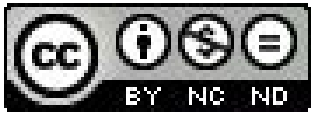

\begin{abstract}
The current paper presents the results from some research on the relationship between Internet addiction, cyberchondria, and different aspects of well-being. The information available on the Internet, which is not necessarily truthful and accurate, can unreasonably amplify users health concerns. Problematic Internet use, health anxiety aroused by online searches for health information and escalation of health concerns as an indicator of cyberchondria, are all associated with a decrease in subjective and eudaimonic well-being as well as in self-esteem. The analyses indicate positive relationships between depressive symptoms on the one hand, and Internet addiction and health anxiety, on the other. A conclusion regarding the existence of a relationship between Internet addiction, cyberchondria and decreased levels of well-being could be drawn from the research. Furthermore, the results suggest that self-esteem and eudaimonic well-being correlate positively with the number of people with whom users communicate online.
\end{abstract}

Key words: Internet addiction, health anxiety, cyberchondria, well-being

\section{INTRODUCTION}

The purpose of this paper is to study the relationships between Internet addiction, cyberchondria and well-being. To broaden the scope of findings, the concept of well-being has been elaborated by measuring subjective well-being, eudaimonic well-being, self-esteem and depression. The assumption is that self-esteem is consistent with well-being, while depression is negatively associated with well-being (Ryff, \& Keyes, 1995; Wood, \& Joseph, 2010).

\section{INTERNET ADDICTION}

There are not only terminological differences between researches in the field of problematic Internet use, but there are also contrasts between their views on the nature of Internet addiction. Most widely the criteria for pathological gambling from DSM-IV have been adapted for problematic Internet use. Thus Internet addiction is commonly defined as impulse control disorder (Young, 1996). As far as the variations of Internet addiction are concerned, there are also some contrasting opinions. David Greenfield (1999) distinguishes between a primary problem and a secondary problem with the Internet. The primary problem is characterized with the Internet itself being the focus of problematic behaviour, while the secondary problem arises when a pre-existing com- 
pulsive behaviour is released via the Internet. According to Greenfield (1999) aspects of the Internet such as: easy access, anonymity, no time and space restrictions, and disinhibition, turn it into an object of addiction and a tool for augmenting it. Richard Davis (2001, as cited in Caplan, 2005), similarly to Greenfield, differentiates between specific and generalized pathological Internet use. The specific pathological use is devoted to a single activity online: gambling, auctions, sexual content and so on. The generalized pathological use is versatile and encompasses many Internet applications.

Internet addiction could be connected with depressive affect, loneliness and unfulfilling relationships (Caplan, 2003, 2005; Young, \& Rodgers, 1998). D. Greenfield (1999) argues that the Internet is used as a coping tool for distraction from negative thoughts and for mood alteration. Kimberly Young (1999) stated that people with low self-esteem and depressive people are highly prone to Internet addiction, because they use the Internet predominantly for communication, in order to cope with their problems or compensate for them online. Findings suggest that users addicted to the Internet are more depressive and mainly introverted, in contrast with users who do not consider themselves problematic (Petrie \& Gunn, 1998, as cited in Widyanto, \& Griffiths, 2005).

Gert-Jan Meerkerk, Regina Eijnden, Ad Vermulst, and Henk Garretsen (2007) established that real time Internet communication could be connected with compulsive tendencies, namely loss of control and preoccupation with the Internet. The authors inferred a relationship between Internet communication and depressive affect for a six-month period. They noted that communicating with strangers is associated with higher depressive affect, than communicating with friends and relatives. Katherine Bessiere, Sara Kiesler, Robert Kraut, and Bonka Boneva (2004) claimed that social skills in real-world situations could benefit from online communication with strangers. In opposition to this view of social compensation is the hypothesis "the rich get richer", according to which people with better interpersonal skills are those who avail themselves of online communication.

In his cognitive-behavioural theory, R. Davis (2001, as cited in Caplan, 2005) contends that depression and loneliness are distant predispositions to problematic Internet use. On the other hand, there is the view that excessive Internet use could lead to social isolation and loneliness, through neglect of important aspects of personal life. K. Young (1999) described the outcomes of Internet addiction as depression, loneliness, joylessness. The typical addiction symptoms are: tolerance, withdrawal, constant increase in the time spent online, unsuccessful attempts to cut down the time online, negative repercussions on other aspects of life. As the addiction intensifies, the user's feelings become more and more negative. In turn, the addicted person tries to compensate by increasing the time spent online, on order to experience positive feelings.

Junghyun Kim, Robert LaRose, and Wei Peng (2009) confirmed both assumptions in their findings. It is not so much the social applications of the Internet, but the entertainment ones, such as downloading of files and watching videos online, that are connected with decreased well-being. Downloading and watching videos are activities associated with loneliness to a greater extent than online communication is. Yair Amichai-Hamburger (2009) shares the opinion that online relationships could have a positive effect on the well-being of people, due to the unique context of openness, self-disclosure and support of the Internet. 


\section{HEALTH ANXIETY}

Health anxiety can be defined as unfounded health concerns for personal health, when there is no pathology, or excessive worries, when there is an insignificant health problem (Lucock \& Morley, 1996, as cited in Gravatt \& Brown, n.d.). Health anxiety varies from occasional worries to intense fear and anxiety, leading to poor well-being (Asmundson, Taylor, Sevgur, \& Cox, 2001, as cited in Gravatts, \& Brown, n.d.). The cognitive-behavioural theory postulates that health anxiety is the result of misinterpreting information regarding a person's own bodily sensations, in line with the arisen concerns for a serious illness (Salkovskis, Warwick, \& Deale, 2003). The desire of people with health anxiety is to find solace in the information they continually look through. But usually the consequences are intensified worries due to anxious people's inaccurate interpretation of medical data or their inability to integrate positive information (Gravatt \& Brown, n.d.).

Mathew Eastin and Natalie Guinsler (2006, as cited in White, \& Horvitz, 2009) registered a relationship between looking for health information online and visiting a doctor, in which health anxiety is a moderator. The findings from Ryen White and Eric Horvitz's (2009) research demonstrate an even distribution between participants who report that their health anxiety decreases after using the Internet and participants who claim that it increases. Trait anxiety could contribute to high levels of health anxiety and the escalation of health concerns caused by information on the Internet.

Finding health information on the Internet could be potentially beneficial to users. Learning more about their own health status and whether they should visit a doctor could lead people to a more responsible attitude towards their condition, such as keeping to a suitable diet, exercising, healthy living, adhering to the prescribed treatment and so on. Another advantage of using the Internet for health related issues is the social support one could receive from others with similar conditions, especially in cases of socially intolerable illnesses or problems which could hardly be discussed in everyday situations. Anonymity in virtual space enables people with stigmatizing problems to overcome the burden of not being able to talk about their condition. Furthermore, by learning more about one's illness, one can better understand the prescribed treatment, become actively involved in it, and thus assist the professionals. Broadening the knowledge of a problem widens the perspective of the person and increases the probability of higher responsibility. The Internet could serve as a tool for empowering patients (Jones, 2000; Powell, Darvell, \& Gray, 2003).

Health oriented websites designed on the principle of self-diagnosis additionally stimulate health anxiety. Furthermore these sites attract people with tendency for cyberchondria, who can only suffer the negative consequences of using such resources (Ryan, \& Wilson, 2008). There is also a possibility of misinterpreting or only partially understanding medical information. The user might be overwhelmed by complex medical terminology and subsequently might become increasingly concerned. The result may be a bleak self-diagnosis (Benigeri, \& Pluye, 2003, as cited in Whites, \& Horvitz, 2009). Further, it should be considered that even if the user were able to fully comprehend the information, there would be a possibility that the patient-doctor relationship might suffer. Patients might unreasonably raise their 
requirements to their doctors, causing tension in the interactions and therefore impeding the healing process. Doctors might perceive patients' Internet research as an indication of mistrust, especially if a patient argues with the specialist and tries to interfere. If a patient decides to believe what they have read online instead of what their doctors say, the outcome might be detrimental on the treatment.

A focus group study by Gunther Eysenbach and Christian Köhler (2002) of two groups of participants, completing health related web search tasks, indicated that users rarely check which organisation is behind the web site and whether the information on it is reliable. People also do not usually enter combinations of words when searching for medical problems, which contributes to the decline in the accuracy of the results. Users are most likely to pick one of the first few results from the search and easily paraphrase their key word, changing the focus of the search (Atkinson, Saperstein, \& Pleis, 2009; Eysenbach, \& Köhler, 2002). G. Eysenbach and C. Köhler (2002) registered that $97 \%$ of the followed links are amongst the first ten results from the search and $71 \%$ are amongst the first five. Moreover, the majority of users look for medical information not in specialized health portals, but rather in the search engines, which display links to all kinds of sources, including forums and blogs (Atkinson, Saperstein, \& Pleis, 2009). Christina Zarcadoolas, Mercedes Blanco, John Boyer and Andrew Pleasant (2002, as cited in Atkinson, Saperstein, \& Pleis, 2009) found that health is one of the main topics being researched on the Internet by the less educated. On the other hand, Nancy Atkinson, Sandra Saperstein, and John Pleis (2009) report more women and people with a bachelor's or higher degree looking for health information online, compared to men and people with lower education. The authors conclude that people who use the Internet daily for at least one hour are prone to search for medical information.

\section{CYBERCHONDRIA}

The term cyberchondria has been used by the researches from Harris Interactive since 1999 (The Harris Poll, 1999) in their research on looking for health information on the Internet. The authors who have carried out the most extensive research on the topic are R. White and E. Horvitz (2009). They define cyberchondria as the "unfounded escalation of concerns about common symptomatology, based on the review of search results and literature on the Web" (White, \& Horvitz, 2009, p. 1). A key concept for understanding cyberchondria is the escalation of concerns, connected with changing the focus of attention from nonspecific symptoms to serious illnesses, following the results of a web search. The authors also single out persistence of concerns, search habits and cognitive bias as vital aspects of cyberchondria.

Hypochondria is typically rare - 1-5\% of the population (Barsky, \& Klerman, 1983) and 3\% of primary care patients (Escobar, Gara, Waitzkin, Silver, Holman, \& Compton, 1998) experience it. It is characterized with fears that insignificant nonspecific symptoms indicate a serious illness (Barsky, \& Klerman, 1983). Hypochondriacs have tendencies for self-examination, self-diagnosis, and are fixated on their own body. They do not trust the assurances of their doctors that they are not ill. The Internet is therefore a stimulating medium for unfounded health concerns. 
R. White and E. Horvitz (2009) conducted a research with 515 Microsoft employees, using their logs from Internet health search as well as administering a questionnaire. The questions relate to online health search behaviour and the impact of the information on health concerns. Participants demonstrated low levels of health anxiety, but escalation of health concerns after web search was registered in one out of every five people. It was confirmed that the escalation of concerns can lead to temporary or long-term increase in the levels of health anxiety and additional doctor visits. A considerable number of the respondents used the Internet as a differential diagnosis tool, by looking through a list of illnesses and deciding which one was applicable to their condition. More than half of the respondents stated that often or sometimes they considered the order of the results from the web search a reflection of the probability of having a certain illness. Biases of judgement, such as availability bias and base-rate neglect, are regarded as important aspects of cyberchondria (White, \& Horvitz, 2009). Availability bias is an increase in the evaluated probability that something will happen, because of recent and intense exposure to particular events. Base-rate neglect is associated with ignoring the low probability that something will happen, on account of viewing evidence in support of the event.

R. White and E. Horvitz (2010) establish an escalation of concerns in two thirds of the cases when a serious illness is mentioned before an alternative explanation for a certain symptom on a web page. Should the alternative explanation precede the serious illness, an escalation is registered in one third of the cases.

\section{OBJECTIVES}

The main objective of this study is to identify and clarify the relationships between Internet addiction, cyberchondria and well-being. In this context, the aim of the research is to examine the relationships between excessive Internet use, using the Internet for health information and well-being indicated by: subjective well-being, eudaimonic well-being, self-esteem and depression.

\section{METHOD}

Participants. The study was conducted in Bulgaria in 2012. We collected data from 378 participants ( $41 \%$ male and $59 \%$ female). According to age, three groups were set apart: up to 20 years of age (34\%), from 21 to 26 years of age (33\%) and over 26 years of age (33\%). As far as marital status was concerned, two groups were formed: living without a partner (73\%) and living with a partner (27\%). According to the education acquired up to the moment, participants were divided into two groups: with secondary education (56\%) and with higher education (44\%). University and high school students composed $47 \%$ of all participants. The distribution of respondents' place of residence is uneven: $72 \%$ live in Sofia (the capital city of Bulgaria), $15 \%$ live in another large city in the country, and 9\% live in a small town and $4 \%$ - in a village. 


\section{MEASURES}

Internet addiction. The Internet Addiction Test (IAT), designed by K. Young (1998, in Widyanto, \& McMurran, 2004), consists of 20 items describing behaviours which depending on their frequency could be linked to different aspects of Internet addiction. Factor analyses revealed six factors: salience, excessive use, neglecting work, neglecting social life, anticipation, and lack of control. For the purpose of the present research, we used a five-point Likert scale ranging from 1 (never) to 5 (always). The score on the IAT ranges from 20 to 100. K. Young defined three groups of users according to the score: 20-39 - an average user without control issues; 40-69 - a user with problems; 70-100 - a user with significant problems due to uncontrolled Internet use.

We included additional questions regarding Internet use from the research of Oliver Egger and Matthias Rauterberg (1996): questions concerning the positive and negative influence of the Internet on users' lives; questions, regarding the number of people with whom users communicate via the Internet, the number of acquaintances made solely on the Internet and the number of Internet acquaintances met in person.

Health anxiety. The second questionnaire measures anxiety aroused by online health information seeking (Gravatt, \& Brown, n.d.). It consists of 14 items concerning the use of Internet for health information, as well as the cognitions and affects provoked by that use. The responses were measured with a five-point Likert scale ranging from 1 (strongly disagree) to 5 (strongly agree). The authors formed three factors: belief that online health information is accurate; extent of online health information seeking; anxiety aroused by online health information seeking.

Cyberchondria. The questions concerning cyberchondria were taken from R. White, and E. Horvitz's (2009) research. We included items concerning users' perceptions of health information on the Internet, their experience with searching the web for health information, and the influence of the Internet on their health concerns. A few different response scales were used: a dichotomous scale with yes/no answers; Likert type scales ranging from 1 (never) to 5 (always) and from 1 (I do not worry at all) to 5 (I worry excessively).

Subjective well-being. The Satisfaction with Life Scale (Pavot, \& Diener, 1993) was used for assessing subjective well-being. The scale consists of five items reflecting satisfaction from the way a person lives their life and from who they are. We applied a five-point Likert scale ranging from 1 (Strongly disagree) to 5 (Strongly agree).

Eudaimonic well-being. The questionnaire measuring eudaimonic well-being was designed by Alan Waterman, Seth Schwartz, Byron Zamboanga, Russel Ravert, Michelle Williams, Bede Agocha, Su Kim, and Brent Donnellan (2010). The authors define eudaimonic well-being as incorporating subjective as well as objective elements. Subjective elements are feelings of personal expressiveness and objective elements are all behaviours directed at self-realisation, through the recognition and development of personal potential, so that one leads a meaningful life. The questionnaire is comprised of 21 items. The scale we applied was a five-point Likert one, ranging from 1 (Strongly disagree) to 5 (Strongly agree). 
Self-esteem. The Rosenberg Self-Esteem Scale (Rosenberg, 1989), consisting of 10 items, was used with a four-point Likert scale ranging from 1 (Strongly agree) to 4 (Strongly disagree).

Depression. We applied the short eight-item version of the Center for Epidemiologic Studies Depression Scale by Lenore Radloff (1977, in Van de Velde, Bracke, \& Levecque, 2008) - CES-D 8. Participants had to answer with regard to their state during the past week. The response scale we used was four-point Likert type ranging from 1 (rarely) to 4 (most of the time).

\section{RESULTS AND DISCUSSION}

The data were analysed with the computer program SPSS.

\section{Internet Addiction}

The conducted research indicates that participants experience problems with their Internet use $(\mathrm{M}=40.23 ; \mathrm{SD}=11.53)$. Those participants who did not demonstrate problematic Internet use were $55 \%$. The problematic users were $43 \%$ of the participants in the study, and the last $2 \%$ experienced significant problems as a result of their online activity. The data shows that generally participants did not display high levels of the factors of Internet addiction described by K. Young (1998, in Widyanto, \& McMurran, 2004) (see table 1).

Table 1. Results from a descriptive analysis of the Internet Addiction Test

\begin{tabular}{|l|c|c|c|c|}
\hline & Mean (M) & $\begin{array}{c}\text { Standard } \\
\text { deviation (SD) }\end{array}$ & Minimum & Maximum \\
\hline Internet addiction & 40.23 & 11.53 & 20 & 86 \\
\hline Salience & 1.73 & 0.65 & 1 & 4.50 \\
\hline Lack of control & 2.28 & 0.89 & 1 & 4.60 \\
\hline Neglecting work & 1.82 & 0.72 & 1 & 5.00 \\
\hline Neglecting social life & 1.92 & 0.72 & 1 & 4.67 \\
\hline Anticipation & 2.22 & 0.86 & 1 & 5.00 \\
\hline Excessive use & 2.19 & 0.70 & 1 & 4.67 \\
\hline
\end{tabular}

Source: Author

The results indicate a tendency for Internet addiction, anticipation of the next session, and use of the Internet for longer than intended, which is connected with lack of control. However, the scores are not high enough to suggest a considerable disturbance in the way of life of respondents due to Internet use.

\section{Health Anxiety}

The data from the questionnaire for health anxiety aroused by online searching for health information were analysed with the methods of descriptive statistics. The levels of: health anxiety $(\mathrm{M}=25.56 ; \mathrm{SD}=7.73)$, belief that online health information is accurate $(M=8.34 ; S D=2.60)$, and extent of online information seeking $(M=7.70$; $\mathrm{SD}=2.61$ ) are moderate. 


\section{Cyberchondria}

The items of the questionnaire for cyberchondria were analysed with the methods of descriptive statistics. It was registered that participants rarely look for health information online $(\mathrm{M}=1.91 ; \mathrm{SD}=3.04)$ and even more so for undiagnosed health issues $(\mathrm{M}=0.96 ; \mathrm{SD}=1.70)$. These results are considerably lower than those reported by R. White and E. Horvitz (2009). Regarding the nature of the health information which participants search for, the results indicated that physical symptoms were what users check online most of the time ( $45 \%$ looked symptoms up online). The findings suggested that $36 \%$ of participants looked for information shared by others with a similar condition to theirs. This might be a possibility for people to be influenced by other nonprofessionals. The results revealed that $33 \%$ of respondents searched for information on diagnosed conditions and $26 \%$ looked for information about serious illnesses. The latter might be an indicator for cyberchondria. In the present study, $6 \%$ of participants defined themselves as hypochondriacs, while $11 \%$ had been referred to as such.

The questions regarding the level of hypochondria and health anxiety, as well as the tendency for reviewing websites for serious illnesses, when looking for information on non-specific symptoms, represent the escalation of health concerns. We found that $34 \%$ of respondents were prone to change the focus of their search, while $26 \%$ claimed they never did that. In contrast with our findings, R. White and E. Horvitz (2009) registered $63 \%$ of users as likely to change the focus of their search. Our Bulgarian sample seems to be stricter in health searches, although the percentage of people who tend to change the search topic from a benign symptom to a serious illness is still considerable.

As for the questions on the topic of persistence of health concerns, we registered that $46 \%$ of users continued to look for information after they had had their doubts raised about a serious illness by information on the Internet. Only 19\% reported having disturbances in their online activities and 14\% experienced disturbances in their usual everyday activities, as a result of raised concerns. $81 \%$ declared that worrying health information rarely or never influenced their online activities and respectively $86 \%$ stated that regarding their offline activities. It can be concluded that respondents are generally more skeptical about a possible connection between the order of the search results and the probability of the illnesses described in each of them. According to $51 \%$ of respondents there was no such connection, while $28 \%$ found it rarely. Only $21 \%$ believed that there was a direct connection between the rank of the result and its relevance for the searched symptom. In R. White and E. Horvitz's (2009) study, 51\% of the sample shared that opinion. In the present study $25 \%$ of respondents used the Internet as a diagnostic tool. This is a premise for the development of unfounded concerns. The powerful influence of Internet information is notable in the following results: $45 \%$ of users visited a doctor after reviewing disturbing health information online and $86 \%$ declared that a checkup reassured them that their concerns were unsubstantiated.

\section{Relationships between Internet addiction, health anxiety, cyberchondria and well-being}

To investigate the relationships between Internet addiction, health anxiety aroused by online health search, and escalation and persistence of health concerns as aspects of cyberchondria, we conducted correlation analyses (see Table 2). 
Table 2. Results from correlation analyses of Internet addiction, health anxiety and cyberchondria

\begin{tabular}{|c|c|c|c|c|c|c|}
\hline & $\begin{array}{l}\text { Internet } \\
\text { addiction }\end{array}$ & $\begin{array}{l}\text { Health } \\
\text { anxiety }\end{array}$ & $\begin{array}{c}\text { Belief that } \\
\text { online health } \\
\text { information is } \\
\text { accurate }\end{array}$ & $\begin{array}{l}\text { Extent } \\
\text { of online } \\
\text { information } \\
\text { seeking }\end{array}$ & $\begin{array}{l}\text { Escalation } \\
\text { of } \\
\text { concerns }\end{array}$ & $\begin{array}{c}\text { Persistence } \\
\text { of } \\
\text { concerns }\end{array}$ \\
\hline Internet addiction & 1 & $0.192^{*}$ & 0.033 & $0.144^{*}$ & $0.267^{* *}$ & $0.171^{* *}$ \\
\hline Health anxiety & & 1 & $0.372^{* *}$ & $0.788^{* *}$ & $0.367^{* *}$ & $0.439^{* *}$ \\
\hline $\begin{array}{l}\text { Belief that online } \\
\text { health information } \\
\text { is accurate }\end{array}$ & & & 1 & $0.486^{* *}$ & $0.108^{*}$ & $0.214^{* *}$ \\
\hline $\begin{array}{l}\text { Extent of online } \\
\text { information } \\
\text { seeking }\end{array}$ & & & & 1 & $0.230^{*}$ & $0.421^{* *}$ \\
\hline $\begin{array}{l}\text { Escalation of } \\
\text { concerns }\end{array}$ & & & & & 1 & $0.354^{*}$ \\
\hline $\begin{array}{l}\text { Persistence of } \\
\text { concerns }\end{array}$ & & & & & & 1 \\
\hline
\end{tabular}

Source: Author

The results showed the following tendencies. Positive relationships were registered between the studied phenomena. We established that Internet addiction was positively correlated with escalations $(r=0.267)$ and persistence $(r=0.171)$ of health concerns as indicators of cyberchondria, with health anxiety $(r=0.192)$, and with the extent to which respondents use the Internet for health information $(r=0.144)$.

As expected health anxiety was correlated with the belief that online health information is accurate $(\mathrm{r}=0.372)$ and with the extent to which Internet is used for health information $(\mathrm{r}=0.788)$. Health anxiety was also correlated with escalation $(\mathrm{r}=0.367)$ and persistence of concerns $(\mathrm{r}=0.439)$. Escalation of concerns correlated with persistence of concerns $(r=354)$, which was also expected, since they are both aspects of cyberchondria. Logically the belief that online health information is accurate was in positive relationship with the extent of online information seeking $(r=0.486)$. We registered weaker correlations between the belief that online health information is accurate and escalation $(r=0.108)$ and persistence of concerns $(r=0.214)$. The extent to which a user looks for health information online was positively correlated with escalation $(r=0.230)$ and persistence $(r=0.421)$ of concerns.

For the revelation of the relationships between Internet addiction, health anxiety, cyberchondria, subjective and eudaimonic well-being, self-esteem and depression, correlation analyses were carried out. The results are presented in table 3 . 
Table 3. Results from correlation analyses of the relationships between Internet addiction, health anxiety, cyberchondria, well-being, self-esteem and depression

\begin{tabular}{|l|c|c|c|c|}
\hline & $\begin{array}{c}\text { Subjective } \\
\text { well-being }\end{array}$ & $\begin{array}{c}\text { Eudaimonic } \\
\text { well-being }\end{array}$ & Self-esteem & Depression \\
\hline Internet addiction & $\mathbf{- 0 . 1 3 4 ^ { * * }}$ & $\mathbf{- 0 . 1 9 9 ^ { * * }}$ & $\mathbf{- 0 . 2 3 1}^{* *}$ & $\mathbf{0 . 2 7 6}^{* *}$ \\
\hline Health anxiety & -0.074 & $\mathbf{- 0 . 1 4 5 ^ { * * }}$ & $\mathbf{- 0 . 1 5 4}^{* *}$ & $\mathbf{0 . 1 5 9}^{* *}$ \\
\hline $\begin{array}{l}\text { Belief that online health } \\
\text { information is accurate }\end{array}$ & 0.006 & 0.042 & 0.030 & 0.011 \\
\hline $\begin{array}{l}\text { Extent of online } \\
\text { information seeking }\end{array}$ & -0.015 & -0.054 & -0.088 & 0.087 \\
\hline Escalation of concerns & $\mathbf{- 0 . 1 3 5 ^ { * * }}$ & $\mathbf{- 0 . 1 6 9 * *}$ & $\mathbf{- 0 . 1 0 7 ^ { * }}$ & $\mathbf{0 . 1 8 7 ^ { * * }}$ \\
\hline Persistence of concerns & -0.060 & -0.102 & -0.014 & $\mathbf{0 . 1 0 8 ^ { * }}$ \\
\hline
\end{tabular}

${ }^{* *} \mathrm{p}<0.01 ;{ }^{*} \mathrm{p}<0.05$

Source: Author

The analyses showed that Internet addiction correlated significantly and positively with depression $(\mathrm{r}=0.276)$ and significantly but negatively with subjective well-being $(\mathrm{r}=-0.134)$, eudaimonic well-being $(\mathrm{r}=-0.199)$ and self-esteem $(\mathrm{r}=-0.231)$. These results, indicating that uncontrolled Internet use is associated with lowered levels of well-being and self-esteem, are consistent with previous research (Young, \& Rogers, 1998; Caplan, 2003, 2005).

Health anxiety was also positively correlated with depression $(\mathrm{r}=0.159)$ and negatively correlated with self-esteem ( $\mathrm{r}=-0.154)$ and eudaimonic well-being $(\mathrm{r}=-0.145)$. Escalation of concerns correlated negatively with both subjective $(\mathrm{r}=-0.135)$ and eudaimonic $(\mathrm{r}=-0.169)$ well-being as well as with self-esteem $(\mathrm{r}=-0.107)$. On the other hand, we registered positive correlations between escalation of concerns and depression $(r=0.187)$ and between persistence of concerns and depression $(\mathrm{r}=0.108)$. These findings suggest that health anxiety and escalation of concerns as an aspect of cyberchondria are negatively associated with well-being and self-esteem and positively - with depression.

To examine the relationships between well-being, self-esteem and depression, on the one hand, and the influence of the Internet and some communication aspects, on the other, we preformed correlation analyses (see Table 4).

The findings show that subjective well-being did not correlate significantly either with perceived positive influence of the Internet or with its negative influence. Eudaimonic well-being was weakly and positively correlated with positive influence of the Internet $(\mathrm{r}=0.112)$ and weakly and negatively correlated with negative influence of the Internet $(\mathrm{r}=-0.162)$. We could speculate that eudaimonic well-being is a more complex construct than subjective well-being which incorporates personal expressiveness as well as development of the personal potential (Waterman, Schwartz, Zamboanga, Ravert, Williams, Agocha, Kim, \& Donnellan, 2010), and therefore eudaimonic well-being more sensitively reflects the influence of the Internet on the person. We could conclude that eudaimonic well-being is connected with the positive influence of the Internet on one's life. The perceived negative influence of using the Internet correlated weakly and negatively with self-esteem $(r=-0.142)$ and positively with depression $(\mathrm{r}=0.177)$. 
Table 4. Results from correlation analyses of positive and negative influence of the Internet, communicational aspects of the Internet, well-being, self-esteem and depression

\begin{tabular}{|c|c|c|c|c|c|c|}
\hline & $\begin{array}{l}\text { Subjective } \\
\text { well-being }\end{array}$ & $\begin{array}{l}\text { Eudaimo- } \\
\text { nic well- } \\
\text {-being }\end{array}$ & Self-esteem & Depression & \begin{tabular}{|c|} 
Positive \\
influence of \\
the Internet
\end{tabular} & \begin{tabular}{|c} 
Negative \\
influence of \\
the Internet
\end{tabular} \\
\hline $\begin{array}{l}\text { Positive } \\
\text { influence of the } \\
\text { Internet }\end{array}$ & 0.053 & $0.112^{*}$ & 0.074 & -0.021 & 1 & $0.145^{* *}$ \\
\hline $\begin{array}{l}\text { Negative } \\
\text { influence of the } \\
\text { Internet }\end{array}$ & -0.075 & $-0.162^{* *}$ & $-0.142 * *$ & $0.177^{* *}$ & $0.145^{* *}$ & 1 \\
\hline $\begin{array}{l}\text { People with } \\
\text { whom I } \\
\text { communicate } \\
\text { via the Internet }\end{array}$ & 0.094 & $0.154^{* *}$ & $0.110^{*}$ & -0.092 & $0.189^{* *}$ & -0.005 \\
\hline $\begin{array}{l}\text { Acquaintances } \\
\text { made on the } \\
\text { Internet }\end{array}$ & -0.040 & 0.067 & 0.053 & -0.007 & 0.080 & $0.139 * *$ \\
\hline $\begin{array}{l}\text { People from } \\
\text { my Internet } \\
\text { acquaintances I } \\
\text { met in person } \\
\end{array}$ & 0.013 & 0.039 & 0.091 & -0.010 & $0.174^{*}$ & 0.001 \\
\hline
\end{tabular}

Source: Author

In summary, the negative effect of the Internet on users' lives was to some extent connected with decreased levels of eudaimonic well-being and self-esteem, and increased levels of depression. We found that perceived positive influence of the Internet correlated weakly but positively with the perceived negative influence of the Internet $(\mathrm{r}=0.145)$. A possible explanation could be that the positive sides of the Internet do not exclude the negative ones and users supposedly realise this. As well as advantages, the Internet has inevitable setbacks - it is time-consuming and as a result users neglect other areas of their lives.

We established that the number of people with whom respondents communicate via the Internet correlated weakly but positively with eudaimonic well-being $(\mathrm{r}=0.154)$, with self-esteem $(\mathrm{r}=0.110)$ and with the perceived positive influence of the Internet $(\mathrm{r}=0.189)$ (see Table 4). These findings are consistent with other research on Internet communication and well-being. Kim, LaRose and Peng (2009) confirmed that it is not the social applications of the Internet, but the entertainment ones, that are connected with decreased well-being. Y. Amichai-Hamburger (2009) underlines the positive effect of online relationships on well-being.

In contrast, the number of acquaintances made solely on the Internet was positively and weakly correlated with the negative influence of the Internet $(r=0.139)$. This result leads us to the conclusions drawn by researches like G. Meerkerk, R.v.d. Eijnden, A. Vermulst, and H. Garretsen (2007), who pointed out that communica- 
tion with strangers is connected with higher depressive affect, than communication with friends. Although we did not establish the same relationship with depressive affect, we did register a connection with the negative effects of the Internet.

Nevertheless, meeting in person people met on the Internet was positively and weakly correlated with the positive influence of the Internet $(r=0.174)$. We could infer that as long as people manage to incorporate their online life with their real life, they would probably perceive positively the Internet experience. As John Suler (1999) states, it is important to integrate the Internet use into the real life, so that the two would complement one another. Meeting the acquaintances made on the Internet and communicating with friends and relatives using the Internet is a way of enriching interpersonal relationships.

\section{CONCLUSION}

The present empirical study, conducted in Bulgarian social and cultural environment, indicates the following main findings. On the basis of the results it can be concluded that participants did not demonstrate high levels of cyberchondria and health anxiety aroused by seeking health information online. The Internet addiction score was just in the group characterized with problematic control over Internet use.

Significant relationships were indentified between Internet addiction, health anxiety aroused by seeking health information online, and escalation of concerns and persistence of concerns as aspects of cyberchondria. Excessive use of the Internet, searching for health information on the Internet, and subsequent worries for the personal health, appear to be all associated with one another. Further looking into the relationships between these phenomena and subjective well-being, eudaimonic well-being, self-esteem and depression, the following was established. Elevated levels of Internet addiction are associated with lower eudaimonic well-being, subjective well-being and self-esteem and higher depressive affect. The same relationships were registered for escalation of health concerns following a web search. As far as health anxiety connected with health information online is concerned, it is associated with decreased eudaimonic well-being and self-esteem, and with increased depressive affect.

Eudaimonic well-being is associated with perceived positive influence of the Internet on personal life. Furthermore, negative influence of the Internet on life is connected with lower levels of eudaimonic well-being and self-esteem and higher levels of depression. The more people with whom a user communicates via the Internet, the higher eudaimonic well-being, self-esteem and positive influence of the Internet are registered. The results suggest that communicating with a lot of people whom the user does not personally know is associated with perceived negative influence of the Internet. On the other hand, meeting in person the people originally met on the Internet, turning them into a part of the real life, is connected with perceived positive influence of the Internet.

The present study builds on previous research regarding Internet use, health anxiety, cyberchondria and well-being by revealing relationships between the phenomena in Bulgarian environment, without the claim to generalise the results. 


\section{REFERENCES}

Amichai-Hamburger, Y., (2009). Technology and Psychological Well-Being. Cambridge: University Press.

Atkinson, N., Saperstein, S., \& Pleis, J. (2009). Using the Internet for health-related activities: findings from a national probability sample. J Med Internet Res, 11(1), e4. Retrieved from http://www.jmir. org/2009/1/e4/.

Barsky, A., \& Klerman, G. (1983). Overview: hypochondriasis, bodily complaints, and somatic styles. Amer. J. Psychiatry, 140(3), 273-283.

Bessiere, K., Kiesler, S., Kraut, R., \& Boneva, B. (2004). Longitudinal effects of Internet uses on depressive affect: a social resources approach. Carnegie Mellon University. Retrieved from http://www.cbdr.cmu.edu/ papers/pdfs/cdr_118.pdf.

Caplan, S. (2003). Preference for online social interaction. A theory of problematic Internet use and psychosocial well-being. Communication Research, 30(6), 625-648.

Caplan, S. (2005). A social skill account of problematic Internet use, Journal of Communication, December, 55(4), 721-736.

Egger, O., \& Rauterberg, M. (1996). Internet behaviour and addiction. Retrieved from http://www.idemployee.id.tue.nl/g.w.m.rauterberg/ibq/report.pdf.

Eysenbach, G., \& Köhler, C., (2002). How do consumers search for and appraise health information on the world wide web? Qualitative study using focus groups, usability tests, and in-depth interviews. Brit. Med. J., 324(7337), 573-577.

Escobar, J., Gara, M., Waitzkin, H., Silver, R.C., Holman, A., \& Compton, W. (1998). DSM-IV Hypochondriasis in Primary Care. Gen Hosp Psychiatry, May, 20(3), 155-159.

Gravatt, S.,\& Brown M., (n.d.). Health anxiety and Internet use. Retrieved from http://homepage.mac. com/psychresearch/Sites/site2/publications/manuscripts/ HealthAnxiety-MJB.pdf.

Greenfield, D. (1999). Virtual addiction: sometimes new technology can create new problems, The Center for Internet Studies @ Psychological Health Associates. Retrieved from http://www.virtual-addiction. com/pdf/nature_internet_addiction.pdf.

Jones, R. (2000). Self care Important for health services and needing more research, BMJ, March 4; 320, 596.

Kim, J., LaRose, R., \& Peng, W. (2009). Loneliness as the cause and the effect of problematic Internet use: the relationship between Internet use and psychological well-being. CyberPsychology \& Behavior, 12(4), 451-455.

Meerkerk, G, Eijnden, R. v. d., Vermulst, A., \& Garretsen, H. (2007). The Compulsive Internet Use Scale (CIUS): some psychometric properties. In: Meerkerk, G. (Ed.) Pwned by the Internet (pp.18-36). Rotterdam: Erasmus University.

Potts, H., \& Wyatt, R. (2002). Survey of doctors' experience of patients using the Internet, J Med Internet Res, 4(1), e5. Retrieved from http://www.jmir.org/2002/1/e5/.

Powell, J., Darvell, M., \& Gray J. (2003). The doctor, the patient and the World-Wide Web: how the Internet is changing healthcare. J $R$ Soc Med, February, 96(2), 74-76.

Ryan, A., \& Wilson, S. (2008). Internet healthcare: do self-diagnosis sites do more harm than good? Expert Opin. Drug Saf, 7(3), 227-229

Ryff, C., \& Keyes, C. (1995). The structure of psychological well-being revisited. Journal of Personality and Social Psychology, 69(4),719-727.

Salkovskis, P., Warwick, H., \& Deale, A. (2003). Cognitive-behavioral treatment for severe and persistent health anxiety (hypochondriasis). Brief Treatment and Crisis Intervention, 3, 353-368.

Suler, J. (1999). To get what you need: healthy and pathological Internet use. Retrieved from http:/ / users.rider. edu/ suler/psycyber/getneed.html.

Kim, J., LaRose, R., \& Peng, W. (2009). Loneliness as the cause and the effect of problematic Internet use: the relationship between Internet use and psychological well-being. CyberPsychology \& Behavior, 12(4), 451-455.

Pavot, W., \& Diener, E., (1993). Review of the satisfaction with life scale. Psychological Assessment, 5, $164-$ 172.

Rosenberg, M. (1989). Society and the adolescent self-image. Revised edition. Middletown, CT: Wesleyan University Press.

The Harris Poll (1999, February 17). Explosive growth of a new breed of "cyberchondriacs". Retrieved from http://www.harrisinteractive.com/vault/Harris-Interactive-Poll-Research-EXPLOSIVEGROWTH-OF-A-NEW-BREED-OF-CYBERCHONDRIACS-1999-02.pdf. 
Van de Velde, S., Bracke, P., \& Levecque, K. (2008). The psychometric properties of the CES-D 8 depression inventory and the estimation of cross-national differences in the true prevalence of depression. Retrieved from http://soc.kuleuven.be/ceso/dagvandesociologie/papers/CESD8\%20in\%20comparative\%20perspective $\% 20$ Vandevelde-Bracke-Levecque.pdf.

Waterman, A. S., Schwartz, S. J., Zamboanga, B. L., Ravert, R. D., Williams, M. K., Agocha, V. Bede, Kim, S. Y., \& Donnellan, M. B. (2010). The questionnaire for eudaimonic well-being: psychometric properties, demographic comparisons, and evidence of validity, The Journal of Positive Psychology, vol. 5, 41-61.

White, R.W., \& Horvitz, E. (2009). Cyberchondria: studies of the escalation of medical concerns in Web search. ACM Transactions on Information Systems, 27(4), 1-37.

White, R.W., \& Horvitz, E. (2010). Predicting escalations of medical queries based on web page structure and content. Retrieved from http://research.microsoft.com/en-us/um/people/horvitz/SIGIR_2010_ page_structure.pdf.

Widyanto, L., \& Griffiths, M. (2005). Internet addiction: a critical review. Int J Ment Health Addict, (2006) $4,31-51$.

Widyanto, L., \& McMurran, M. (2004). The psychometric properties of the Internet addiction test. Cyber Psychology and Behavior, 7, 443-450.

Wood, A., \& Joseph, S. (2010). The absence of positive psychological (eudemonic) well-being as a risk factor for depression: A ten year cohort study. Journal of Affective Disorders, 122(3), 213-217.

Young, K. (1996). Internet addiction: the emergence of a new clinical disorder, Cyber Psychology and Behavior, 1(3), 237-244.

Young, K., \& Rodgers, R. (1998). The relationship between depression and Internet addiction. CyberPsychology \& Behavior, 1(1), 25-28.

Young, K. (1999). Internet addiction: symptoms, evaluation, and treatment. Professional Resource Exchange. Retrieved from http:// www.netaddiction.com/articles/symptoms.pdf 